\title{
The Isolation and Identification of a Hydrojuglone Glycoside Occurring in the Walnut
}

\author{
By C. DAGLISH \\ The Ovaltine Research Laboratories, King's Langley, Herts
}

(Received 7 February 1950)

In a preliminary note (Daglish \& Wokes, 1948) it was shown that the 'apparent vitamin C' of the walnut (Juglans regia) (Wokes, Organ, Duncan \& Jacoby, 1943) was probably a hydrojuglone derivative. The evidence for this was based upon the findings that solutions of the substance separated by chromatography showed an ultraviolet absorption curve similar to those of reduced acetoxyjuglone and $\alpha$ hydrojuglone, and on hydrolysis yielded juglone. This work has now been extended, and it appears that this substance is glycosidal in nature with the sugar moiety attached to the 5-hydroxyl of 1:4:5-trihydroxynaphthalene. This paper describes the work leading to its isolation and identification.

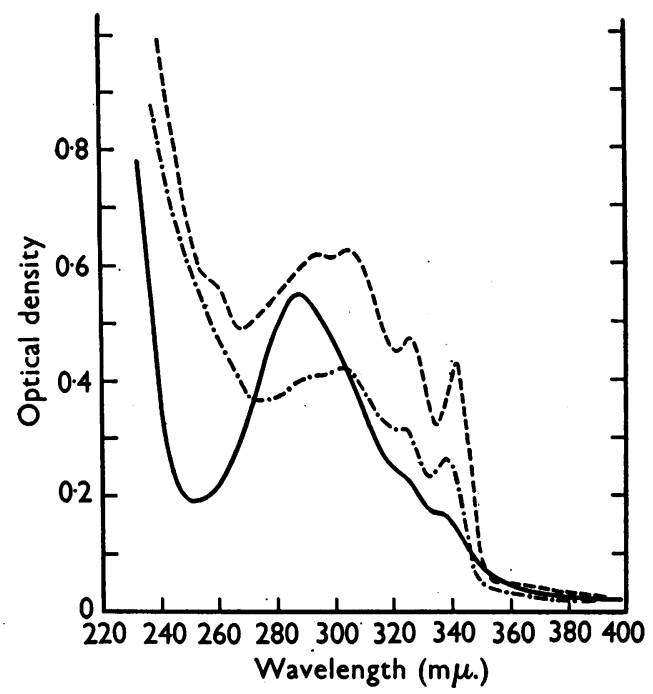

Fig. 1. Absorption curves in $0.03 \mathrm{~N}$ ethanolic $\mathrm{HCl}$ of: - aqueous extract of stem cortex and phloem; ,$--- 0 \cdot 27 \mathrm{~N}$ ethanolic $\mathrm{HCl}$ extract of mesocarp; -.-.-,$- 5 \%$ $\mathrm{HPO}_{3}$ extract of mesocarp.

\section{EXPERIMENTAL}

Methods. The following is a brief outline of the general procedure, each step of which will be amplified later. An acid ethanol extract adjusted to $\mathrm{pH} 4$ and $60 \%$ ethanol was added to an $\mathrm{Al}_{2} \mathrm{O}_{3}$ column and washed through with more $60 \%$ ethanol. Most of the reducing activity of the original extract was found in the percolate which was then evaporated under reduced pressure until all the ethanol and most of the water had been removed. The concentrated aqueous residue was then extracted with ethyl acetate which was washed to remove salts, sugars, etc., dried, concentrated, and the crude glycoside precipitated with light petroleum.

The percolate from the column when examined in a Beckman spectrophotometer showed a well defined absorption curve with peaks at $225,308,326$ and $341 \mathrm{~m} \mu$. (Fig. 2). Further adsorption on $\mathrm{Al}_{2} \mathrm{O}_{3}$ or freshly precipitated $\mathrm{BaSO}_{4}$ showed that as these peaks exhibited constant relative in. tensities they probably belonged to a single substance. Spectrophotometric methods were used to follow all steps in its isolation.

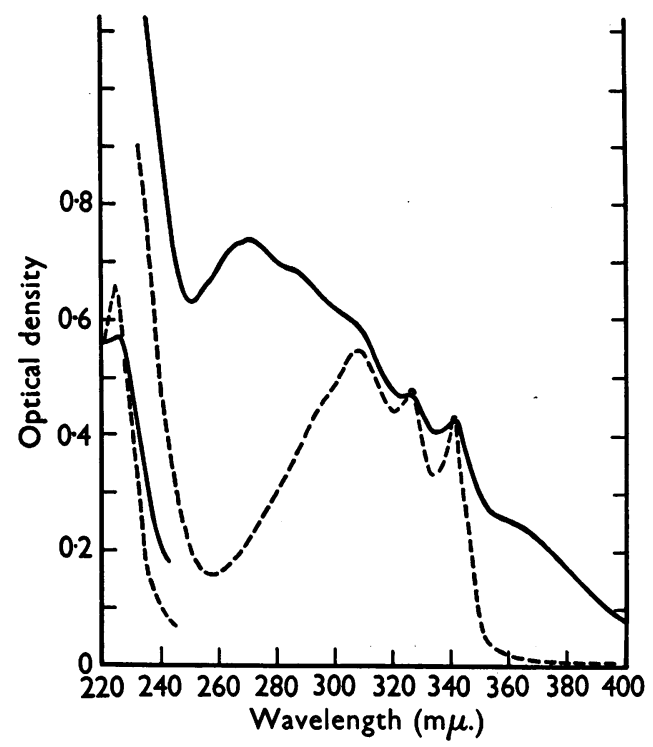

Fig. 2. Absorption curves in $0.03 \mathrm{~N}$ ethanolic $\mathrm{HCl}$ of: $\longrightarrow$, original catkin extract; - - , percolate from column.

\section{Preparation and properties of extracts}

Freshly gathered material was dissected into the solvent, weighed, and then ground with washed quartz in a glass mortar. The extract so obtained was filtered at the pump and the residue in the filter washed with more solvent. The suction was cut off before all the liquid had filtered and the residue was returned to the mortar for further extraction. This was repeated until the material was exhausted and an approximately 1 in 10 extract was obtained. At all times the bruised plant material was covered with solvent to prevent access of air. If the extracts had to be stored they 
were kept in amber bottles, well filled, under $\mathrm{N}_{2}$ and in the refrigerator.

It was necessary to select solvents which would reduce enzyme action and atmospheric oxidation, and maintain the active material in the same state as it was found in the plant.

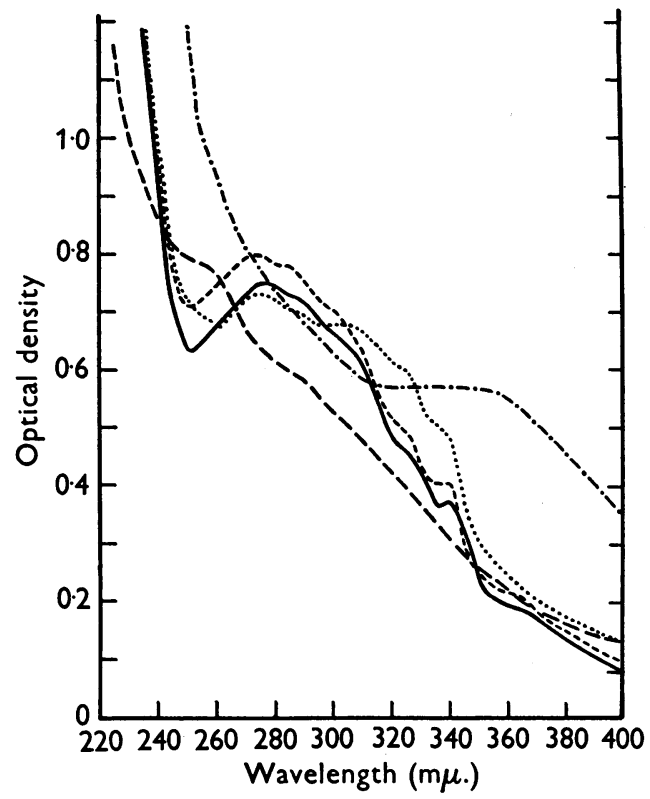

Fig. 3. The effect of $\mathrm{pH}$ on the absorption curve of a bud extract:,$- 0.03 \mathrm{~N}$ ethanolic $\mathrm{HCl} ;---, 0 \cdot 1 \mathrm{~N}-\mathrm{H}_{2} \mathrm{SO}_{4}$ and $\mathrm{pH} 6.0 ; \ldots . ., \mathrm{pH} 8 \cdot 0 ;-.-.-, 0.1 \mathrm{~N}-\mathrm{NaOH}$; - 一, $0 \cdot 1 \mathrm{~N}-\mathrm{H}_{2} \mathrm{SO}_{4}$ added to dilution in $0 \cdot 1 \mathrm{~N}-\mathrm{NaOH}$.

Of those tried, ethanol containing $\mathrm{HCl}$ was found to be the best. It yielded clear extracts suitable for spectrophotometry and for dye titrations. As little as $1 \mathrm{ml}$. A.R. conc. $\mathrm{HCl} / 1.95 \%$ ethanol $(0.03 \mathrm{~N})$ was found to be sufficient to stabilize most extracts, but this proportion was increased to $1 \%(v / v)$ for the extraction of mesocarp and mesophyll which contained sufficiently large quantities of water to retard penetration by the solvent. The use of aqueous solutions of acids gave turbid extracts which were slow to filter. Extracts prepared with a number of extractants, when diluted in $0.03 \mathrm{~N}$ ethanolic $\mathrm{HCl}$ and examined spectroscopically gave very similar curves (Fig. 1), and it seemed probable that no change had taken place during extraction.

When stored in the dark at $\mathrm{pH} 5$ or less, acid ethanol extracts were remarkably resistant to atmospheric oxidation. This was shown by aerating a mesocarp extract for $2-3 \mathrm{hr}$. at the pump until its volume had been reduced to half. Although the colour changed from pale yellow-green to bright yellow, spectroscopic examination showed that there was no loss of activity. However, when a second portion of the same extract was exposed to diffused daylight, a loss of $5.6 \%$ occurred after 1 day and $19 \%$ at the end of a week. In contrast, the percolate obtained from chromatographing this same extract showed a loss of $40 \%$ on aeration for $2 \mathrm{hr}$.

Alteration of the $\mathrm{pH}$ caused considerable change in the absorption curve (Fig. 3) with loss of activity. These changes were not reversible if the $\mathrm{pH}$ exceeded 8 for more than a few minutes. Hence the original extract probably contained a natural anti-oxidant which protected the glycoside, but was itself destroyed by alkali.

\section{Chromatography and stability of the percolate}

The low concentration of the glycoside $(0 \cdot 2-0 \cdot 6 \%$ in most walnut tissues) and the presence of other constituents in much larger proportions, made chromatography the only satisfactory method of separation. The method used to isolate the glycoside is shown by the following example.

Male catkin buds (387 g.) were extracted into $3 \cdot 74$ 1. $0 \cdot 27 \mathrm{~N}$ ethanolic $\mathrm{HCl}$. By spectrophotometric assay, this extract contained $17 \cdot 2 \mathrm{~g}$. glycoside. $3 \cdot 65 \mathrm{l}$. were diluted with $1 \cdot 1 \mathrm{l}$. water and then $328.5 \mathrm{ml}$. $\mathrm{N}-\mathrm{NaOH}$ added. After $15 \mathrm{~min}$. the sludge was filtered off and the green-brown filtrate added to three columns $\left(25 \times 5 \mathrm{~cm}\right.$.) of $\mathrm{Al}_{2} \mathrm{O}_{3}$ protected from light by paper. $\mathrm{N}_{-}-\mathrm{H}_{2} \mathrm{SO}_{4}(2 \mathrm{ml}$.) was added to each receiver which was connected to a water pump. After all the extract had been added, the columns showed three coloured zones, a green one extending a third the length of the column, below it a narrow yellow one, whilst the rest of the column was a diffused pink colour. Washing with $60 \%$ ethanol brought down this pink zone as a pale yellow percolate, which on

\section{Table 1. Variation of percentage recovery of glycoside with conditions of adsorption}

$\left(\mathrm{Al}_{2} \mathrm{O}_{3}\right.$ : sample 1 is from Peter Spence and Sons Ltd., 'for chromatographic purposes'. Sample 2 is from Savory and Moore Ltd. 'for chromatographic analysis'.)

\begin{tabular}{|c|c|}
\hline $\begin{array}{c}\mathrm{Al}_{2} \mathrm{O}_{3} \\
\text { sample }\end{array}$ & Treatment \\
\hline 1 & Dried $24 \mathrm{hr}$. at $105^{\circ}$ \\
\hline 1 & Dried at $24 \mathrm{hr}$. at $105^{\circ}$ \\
\hline 1 & Dried $24 \mathrm{hr}$. at $105^{\circ}$ \\
\hline 1 & As received \\
\hline 1 & Dried $24 \mathrm{hr}$. at $105^{\circ}$ \\
\hline 2 & Dried $24 \mathrm{hr}$. at $105^{\circ}$ \\
\hline 2 & Washed in $60 \%$ ethanol, dried $24 \mathrm{hr}$. \\
\hline 2 & Diluted with $50 \%$ keiselguhr \\
\hline 2 & As received \\
\hline 2 & As received \\
\hline 2 & As received \\
\hline 2 & As received \\
\hline$\overline{2}$ & Dried $24 \mathrm{hr}$. at $105^{\circ}$ \\
\hline 2 & Dried $24 \mathrm{hr}$. at $105^{\circ}$ \\
\hline
\end{tabular}

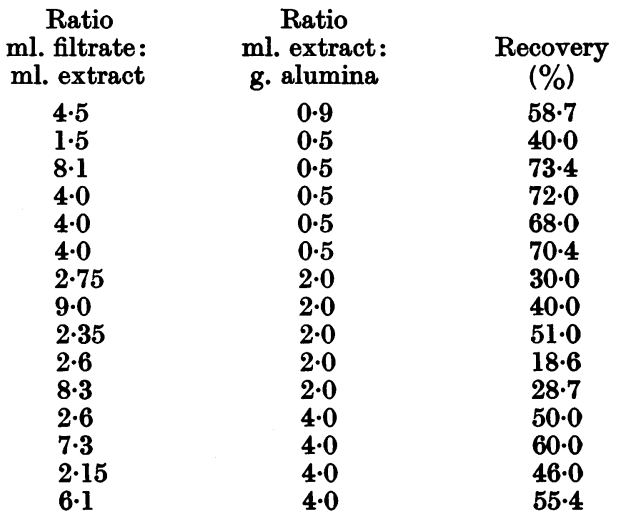


mixing with the mineral acid in the receiver, turned to a bright yellow-green. The percolate (from the extract as well as the ethanolic washings) was collected in 11 . fractions and exch assayed. The first 61 . contained $11.12 \mathrm{~g}$. glycoside. The fractions following contained further quantities, but as the concentration was only 86-90 mg./l., these were discarded. The recovery from the columns of $64.6 \%$ of the activity agreed favourably with the results from smaller columns (Table 1).

The 6 l. of percolate were evaporated at $35-40^{\circ}$ to $700 \mathrm{ml}$. when a considerable amount of the glycoside was deposited on the sides of the flask as a green resin. This was taken up in ethyl acetate, and the yellow aqueous concentrate extracted seven or eight times with the same solvent after partially saturating with $\mathrm{Na}_{2} \mathrm{SO}_{4}$. The combined solvent layers were washed thrice with brine, dried over anhydrous $\mathrm{Na}_{2} \mathrm{SO}_{4}$, evaporated under reduced pressure to $50 \mathrm{ml}$. and then added with shaking to $250 \mathrm{ml}$. light petroleum (b.p. $60-80^{\circ}$ ). Glycoside (9.5 g.) was thus precipitated as a light grey-green mass (estimated spectroscopically to be $97 \%$ pure).

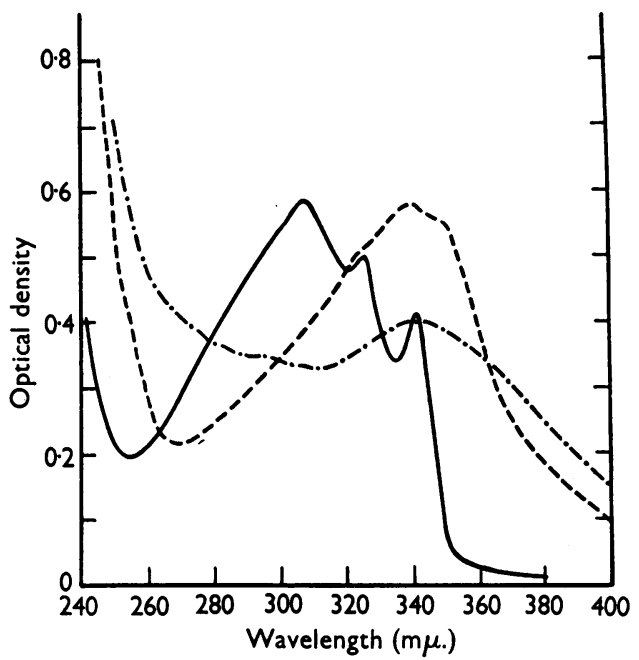

Fig. 4. The effect of buffer $\mathrm{pH} 8$ on the absorption curve of a mesocarp percolate: $\longrightarrow, 0 \cdot 27 \mathrm{~N}$ ethanolic $\mathrm{HCl}$; - pH 8 immediately; -.-.-, pH 8 after 2 hr.

Unless protected from light, the pink zone of the columns rapidly turned blue and could then only be eluted with ethanol containing acid. Similarly, the pale yellow percolate, if not acidified immediately, changed through pale blue to deep indigo and if left for some time, faded through pinkmauve to brown. With these colour changes there was a corresponding change in the ultraviolet absorption curve (Fig. 4), showing that the glycoside had been irreversibly oxidized. Washing the $\mathrm{Al}_{2} \mathrm{O}_{3}$ to remove all traces of alkali rendered it useless. Table 1 gives the results obtained by varying the conditions of adsorption with two commercial samples of alumina, and shows that $60-70 \%$ recovery is possible.

\section{Purification and characterization of the glycoside}

All attempts to obtain a crystalline product having so far failed, the material precipitated as above, after washing with light petroleum and removing the solvent in vacuo, was purified as follows. It was dissolved at $70^{\circ}$ in $0.25 \% \mathrm{SnCl}_{2}$ solution containing a few drops $\mathrm{HCl}$, stirred with charcoal, filtered and chilled, when it came down as a light buff to grey coloured powder. This treatment was repeated until there was no further rise in the melting point or in the intensity of absorption at $341 \mathrm{~m} \mu$. The final yield was $8 \mathrm{~g}$.

When leaves were used as a source of the glycoside, especially during the period from June to September, a second substance was also precipitated from the ethyl acetate. This could be separated by extracting with $\mathrm{CHCl}_{3}$, in which the glycoside is insoluble, to give a cream-coloured powder, m.p. $79-80^{\circ}$.

The glycoside thus purified, was a pale buff-coloured powder, m.p. $165^{\circ}$ (decomp.), extremely soluble in ethanol, methanol, ethyl acetate and acetone; less soluble in water (though the solubility is increased by lowering the $\mathrm{pH}$ ), and insoluble in ether, $\mathrm{CHCl}_{3}$, benzene and light petroleum. The colour of its solutions varied with the solvent, being yellowbrown in water and ethanol, green in wet ethyl acetate but yellow in the dry solvent, and bright yellow-green in dilute acids. The impure compound was extremely hygroscopic, but the material purified as above was fairly stable.

$\mathrm{N}, \mathrm{S}, \mathrm{P}$ and the halogens were shown (Na fusion) to be absent. The molecular weight by the Rast camphor method was 334, whilst values of 329,341 and 343 were obtained by comparing the intensity of absorption at 308, 326 and $341 \mathrm{~m} \mu$. with that at 305,322 and $338 \mathrm{~m} \mu$. for 5 -acetoxy1:4-dihydroxynaphthalene. (Found: C, 57.5; H, 5.8. $\mathrm{C}_{18} \mathrm{H}_{18} \mathrm{O}_{8}$ requires: $\mathrm{C}, 56 \cdot 8 ; \mathrm{H}, 5 \cdot 3 \%$. Mol. wt., 338.)

Aqueous solutions of this compound showed strong reducing properties, reducing permanganate and ammoniacal silver nitrate in the cold and Fehling solution with slight warming. $\mathrm{FeCl}_{3}$ solution gave an intense yellow colour to the solution. Titration with $\mathrm{I}_{2}$ in the presence of $\mathrm{NaHCO}_{3}$ gave an equivalent weight of 169 , whilst acidification and ether extraction of the oxidized solution gave an ethereal solution of juglone which was identified as such both chemically and spectroscopically.

The formation of juglone (5-hydroxy-1:4-naphthoquinone) as an oxidation product tentatively suggested that the compound was a derivative of the reduced form of this, or, $\mathrm{C}_{10} \mathrm{H}_{5}(\mathrm{OH})_{2} \mathrm{O}-\mathrm{C}_{6} \mathrm{H}_{11} \mathrm{O}_{5}$. Further evidence lending weight to this suggestion was obtained by a study of the optical properties of the compound and by its hydrolysis.

In $0.27 \mathrm{~N}$ ethanolic $\mathrm{HCl}$ the compound gives a well defined absorption curve with:

$$
\begin{array}{lrrcc}
\lambda_{\max }(\mathrm{m} \mu .) & 225 & 308 & 326 & 341 \\
E_{1 \%}^{1 \%} \mathrm{~cm} . & 1,246 & 231 & 206 \cdot 5 & 174 \cdot 2 \\
\epsilon & 42,100 & 7,820 & 6,980 & 5,886
\end{array}
$$

In aqueous acid solution there is a slight shift to shorter wavelengths:

$$
\begin{array}{lrrrr}
\lambda_{\max }(\mathrm{m} \mu .) & 224 & 306 & 323 & 338 \\
E_{1 \%}^{1 \%} . & 1,474 & 227 & 195 & 161 \\
\epsilon & 49,780 & 7,670 & 6,590 & 5,430
\end{array}
$$

Fig. 5 gives the curve in acid ethanol together with those for $\alpha$ - and $\beta$-hydrojuglones and 5-acetoxy-1:4-dihydroxynaphthalene. This shows that it is not as first suspected a mixture of sugar and $\alpha$-hydrojuglone but a separate entity with a distinct resemblance to the 5-substituted hydroquinone. Nor is it the quinhydrone of juglone, for when this 
was prepared it was a green compound which in the acid ethanol gave:

$$
\begin{array}{llllll}
\lambda_{\max }(\mathrm{m} \mu .) & 261 & 285 & 335 & 351 & 368 \\
E_{1 \mathrm{~cm} .}^{1} \% & 603 & 360 & 193 & 249 & 266
\end{array}
$$

In a recent paper (Daglish, 1950) it was shown that with substituted 1:4-dihydroxynaphthalenes, when the substituent was in the same ring as the two hydroxyls, an absorption curve was obtained which was distinct from that obtained when the substituent entered the other ring. Since the isolated compound gives a curve showing similarity with a 5- and not a 2-substituted 1:4-naphthohydroquinone, it would appear that the substituent group is in the 5- or possibly the 6-position of the naphthalene nucleus.

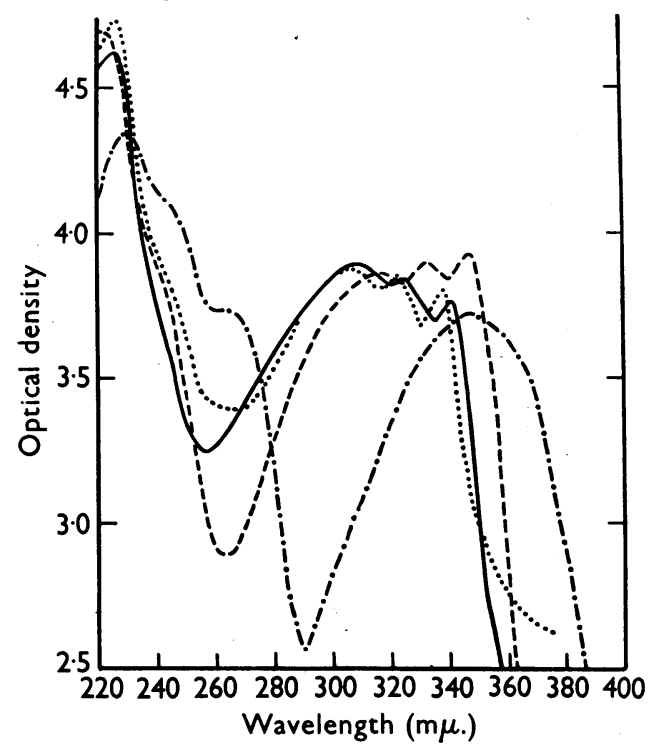

Fig. 5. Absorption curves in $0.03 \mathrm{~N}$ ethanolic $\mathrm{HCl}$ of: $\longrightarrow$, glycoside; - - , $\alpha$-hydrojuglone; -.-.-, $\beta$ hydrojuglone; ...., 1:4-dihydroxy-5-acetoxynaphthalene.

The glycoside (500 mg.) was hydrolysed by refluxing with $10 \mathrm{ml} .2 \mathrm{~N}-\mathrm{H}_{2} \mathrm{SO}_{4}$ for $16 \mathrm{hr}$. After $3 \mathrm{hr}$. a fine black precipitate settled out. This was probably a condensation product of 5-hydroxymethylfurfural with the liberated hydroxynaphthaleme. In order to minimize the amount of this formed, the acid solution was shaken out after $7 \mathrm{hr}$., with an equal volume of ether. This was repeated until the ethereal layer was colourless. The combined ethereal extracts were washed with 2-3 ml. water, and this was added to the original solution which was returned to the steam bath. After completion of hydrolysis, the filtered acid solution was again extracted with ether, the excess $\mathrm{H}_{2} \mathrm{SO}_{4}$ precipitated with the calculated amount of $\mathrm{Ba}(\mathrm{OH})_{2}$ and the filtrate evaporated under reduced pressure to a pale yellow syrup.

The ethereal extracts gave an absorption curve which was indistinguishable from that of $\alpha$-hydrojuglone. Removal of the ether yielded a tan-coloured residue which crystallized from light petroleum (b.p. $40-60^{\circ}$ ) as colourless needles (80 mg.) (m.p. $147^{\circ}$; mixed m.p. with 1:4:5-trihydroxynaphthalene, $147^{\circ}$ ). On oxidation with $\mathrm{FeCl}_{3}$ these gave juglone as yellow needles which was again identified by its characteristic absorption curve, and by the fact that the m.p. $\left(151^{\circ}\right.$, with bath preheated to $\left.140^{\circ}\right)$, was not depressed by admixture with an authentic sample.

Whereas the original glycoside had shown $[\alpha]_{D}^{20^{\circ}}-52.5^{\circ}$ in $0.27 \mathrm{~N}$ ethanolic $\mathrm{HCl}$, an aqueous solution of the syrup showed a positive rotation. It also gave positive reactions with the Molisch and Barfoed reagents. Pentoses were absent, as shown by the absence of a red colour with aniline and $\mathrm{HCl}$ on boiling. When tested with ammonium molybdate and acetic acid the blue colour produced was no greater than that produced by pure glucose. It would thus appear as though the syrup were that of an aldose sugar.

The remainder of the aqueous solution was treated with phenylhydrazine hydrochloride and sodium acetate. An osazone crystallized in $15 \mathrm{~min}$. After recrystallizing from ethanol this melted at $204^{\circ}$. When examined under the microscope, the crystals were indistinguishable from those of glucosazone (m.p. 204 ${ }^{\circ}$ ) prepared at the same time. (Found: C, 60.3; $\mathrm{H}, 6 \cdot 0$. Calc. for $\mathrm{C}_{18} \mathrm{H}_{22} \mathrm{O}_{4} \mathrm{~N}_{4}$ : C, 60.3; H, $6 \cdot 1 \%$.)

The syrup from a second such hydrolysis when heated with $3 \mathrm{ml}$. ethanol and $250 \mathrm{mg}$. $p$-nitrophenylhydrazine for $10 \mathrm{~min}$. yielded a $p$-nitrophenylhydrazone, m.p. $177^{\circ}$. This after recrystallization from ethanol had m.p. $188^{\circ}$; mixed m.p. with glucose $p$-nitrophenylhydrazone, $188^{\circ}$.

The original compound (500 mg.) boiled with an equal weight of anhydrous sodium acetate and $2 \mathrm{ml}$. acetic anhydride for 5 min. and then poured into water yielded a paleyellow gummy mass, which on standing in an ice bath turned to a pale-cream solid. This was readily soluble in hot ethanol, but came down as a white amorphous mass on cooling. Repetition of this treatment gave $375 \mathrm{mg}$. of the hexaacetate of the glycoside, m.p. 75-76 ${ }^{\circ}$. (Found: C, 57.1; H, 5.3; acetyl, 60.3. $\mathrm{C}_{28} \mathrm{H}_{30} \mathrm{O}_{14}$ requires: $\mathrm{C}, 57 \cdot 1 ; \mathrm{H}, 5 \cdot 1$; acetyl, $60.0 \%$.) This compound no longer showed a reducing action.

Attempts to isolate the oxidized or quinone form of the glucoside obtained by the use of oxidizing agents were unsuccessful. After leaving an ethanolic solution of the reduced form in the refrigerator for several weeks in order to induce crystallization, a few bright yellow crystals, m.p. $258^{\circ}$, were obtained. These were shown to be the quinonoid form of the glucoside, but were extremely unstable to light, so much so that it was impossible to obtain a complete absorption curve. Fig. 6 gives the curve for the products of hydrolysis and also shows that the original material had a peak at $275 \mathrm{~m} \mu$. The final solution gave the characteristic curve of juglone. Thomson (1949) showed that dilute solutions of juglone acetate underwent hydrolysis in a similar manner. As this latter hydrolysis was sufficiently slow to be followed spectroscopically in contrast with that of the glucoside, the process was investigated and as the results in Fig. 7 show the hydrolysis is accompanied by reduction.

\section{Attempted synthesis of the glucoside}

Juglone (1.74 g., synthesized by the method of Bernthsen \& Semper, 1887) was dissolved in $150 \mathrm{ml}$. redistilled acetone, and with a stream of $\mathrm{N}_{2}$ agitating the solution $10 \mathrm{ml}$. N ethanolic $\mathrm{KOH}$ was added dropwise. To the purple-coloured suspension, a solution of $4 \cdot 11 \mathrm{~g}$. tetraacetylbromoglucose in $25 \mathrm{ml}$. $\mathrm{CHCl}_{3}$ was added over $45 \mathrm{~min}$. The mixture was left in the dark for $16 \mathrm{hr}$. by which time the colour had changed to light brown. It was filtered and the solvent removed from the filtrate under reduced pressure to give 
$2.8 \mathrm{~g}$. of tarry residue. This was extracted with $100 \mathrm{ml}$. warm ethanol. The ethanol solution, which presumably contained the 5-(tetraacetylglucoside) of 1:4:5-trihydroxynaphthalene, when examined spectroscopically showed a curve almost identical with that of the natural glucoside. The intensity of -bsorption was equal to that given by $318 \mathrm{mg}$. of this compound, but so far, attempts to obtain the synthetic glucoside pure or to acetylate it to the hexaacetate have failed.

The spectroscopic and chemical evidence points to the original compound as being the 5-glucoside of 1:4:5-trihydroxynaphthalene.

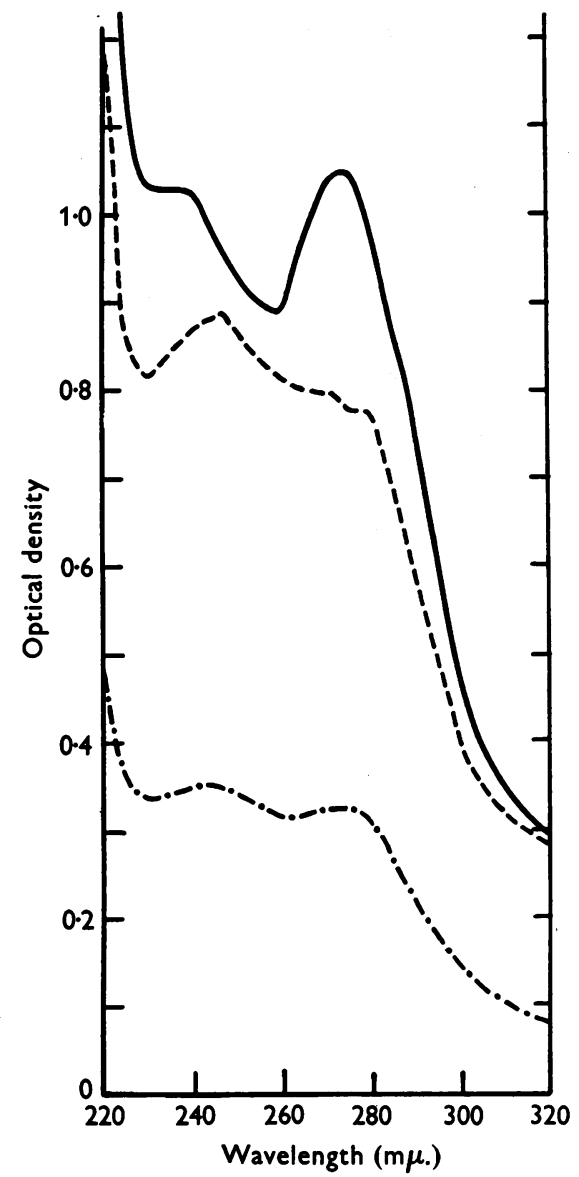

Fig. 6. Absorption curves of oxidized form of the glycoside: - , immediately; - - , after 5 min.; -..-- , fresh dilution.

\section{DISCUSSION}

The occurrence of juglone in the walnut was first reported in 1856 by Vogel \& Reischauer, who gave the name nucin to the yellow crystalline compound isolated from the pericarp. Bernthsen \& Semper (1887) determined its structure as 5-hydroxy-1:4naphthoquinone which was confirmed by its synthesis. Mylius (1885), in the meantime, had reported that juglone did not exist as such in the walnut, but as the reduced form, $\alpha$-hydrojuglone together with a small proportion of the $\beta$-modification. He suggested that these occurred in all green growing parts of the plant, but as ripening proceeded they were converted into complicated compounds. Bernthsen \& Semper (1885), whilst agreeing that juglone existed in the reduced form, doubted the presence of complicated compounds. They suggested that as walnut leaves were rich in inositol it was only necessary to postulate the occurrence of readily hydrolysable inositol glycosides, for merely extracting with ether gave free juglone. Although no chemical evidence was put forward to substantiate this proposition it was revived by Tunman \& Rosenthaler (1931) in the words 'it is not improbable that the $\alpha$ - and $\beta$-hydrojuglones exist as glycosides'.

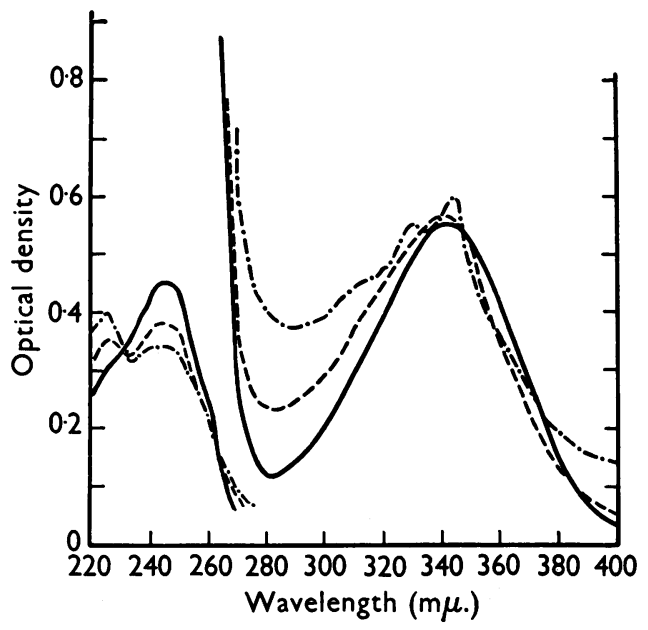

Fig. 7. Hydrolysis of juglone acetate in ethanol: ——, freshly prepared solution; ---, after 8 days; -.-.-., after 30 days. Left-hand curve is 2-15 dilution of that on right.

Coombes (1907), on the other hand, differed from the German workers and suggested that juglone existed preformed in all green parts of the plant, from which it could be extracted as such if the material were fresh. If, however, the plant parts were first dried then hydrojuglone was produced by interaction of juglone with reducing substances formed on drying.

The apparent contradictions can be explained by the present findings. The absorption curves of Fig. 5 show that there are distinct differences in the location of the peaks of the glucoside and of the $\alpha$ and $\beta$-hydrojuglones, so that if these substances were present in walnut extracts it would be possible to distinguish them. The $\beta$-isomer is prepared in vitro by vacuum distilling the $\alpha$-isomer, and is a yellow, chloroform-soluble, non-reducing crystalline compound, fairly stable in ethanolic solutions, but which in acid ethanol slowly reverts to the $\alpha$-isomer as shown in Fig. 8. 
Willstatter \& Wheeler (1914) concluded that the isomerism of the hydrojuglones was one of the ketoenol type, and that the compounds had structures represented by the following formulae:<smiles>Oc1ccc(O)c2c(O)cccc12</smiles>

$\alpha$<smiles>O=C1C=CC(O)c2c(O)cccc21</smiles>
$\beta$<smiles>O=C1CC=C(O)CC1</smiles>

$\mathrm{OH} \mathrm{OH}$
Examination at intervals extending over several days, of extracts from various parts of the plant, has failed to show the presence of the free $\alpha$-isomer, or

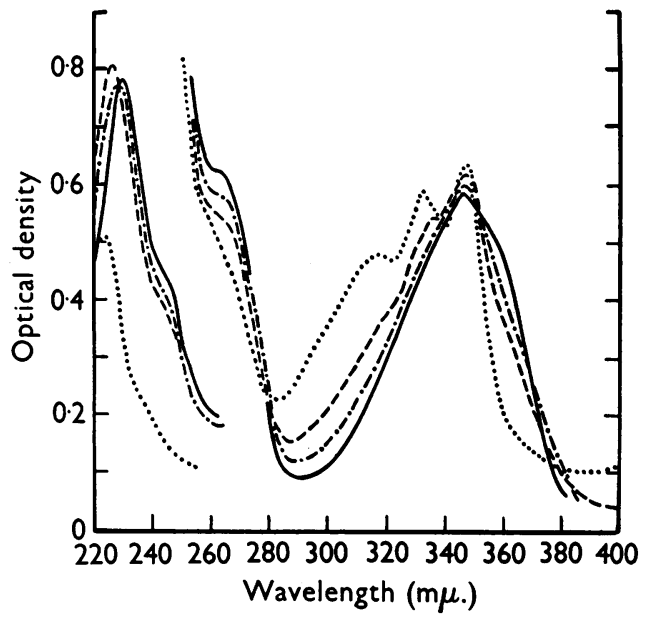

Fig. 8. The effect of time on the absorption curve of a $0.27 \mathrm{~N}$ ethanolic $\mathrm{HCl}$ solution of $\beta$-hydrojuglone: - , immediately; -.-.-, $3 \mathrm{hr}$.; -- -, $7 \mathrm{hr}$.; ...., $23 \mathrm{hr}$. Lefthand curve is $3-10$ dilution of that on right.

the change in the absorption curve which would accompany the reversion of the $\beta$ - to the $\alpha$-form. Hence it would appear that these substances are not present in the free state. The findings of the earlier workers are thus explained by the extreme lability of the glucoside and by the methods of extraction used. In all cases the pericarp was allowed to soak in the extractant which was replaced by fresh solvent after saturation. No details are given of precautions taken against oxidation, so that the extracted substance would be free juglone obtained by the oxidation and hydrolysis of the glucoside. The stannous chloride-hydrochloric acid treatment of Mylius (1885) would reduce this to the $\alpha$-isomer, which is readily soluble in the ether used in the next step of the extraction. The free juglone, in the method of Coombes (1907), was separated as the copper salt and this decomposed with nitric acid, which reagent would oxidize any hydrojuglone present.

The free $\beta$-isomer in Mylius's (1885) extraction was probably formed by the hydrolysis of the glucoside, for he showed that it could be obtained by hydrolysis of acyl derivatives of the $\alpha$-isomer. Alternatively, it may come from some complex in the same way as the $\alpha$-hydrojuglone. So far no compound has been shown to exist in walnut extracts with an absorption curve resembling that of $\beta$-hydrojuglone acetate with peaks at 224,250 and $306.5 \mathrm{~m} \mu$. This compound, colourless needles, m.p. $144^{\circ}$, was prepared by Thomson (1950) during an investigation on the structure of $\beta$-hydrojuglone and related compounds.

\section{SUMMARY}

1. An amorphous compound $\mathrm{C}_{18} \mathrm{H}_{18} \mathrm{O}_{8}$ has been isolated from ethanolic hydrochloric acid extracts of the walnut by chromatography on alumina.

2. Spectroscopic examination suggests that this existed as such in the original plant.

3. On hydrolysis it yielded glucose and $\alpha$-hydrojuglone.

4. Further chemical and spectroscopic evidence suggests that this compound is the 5-glucoside of 1:4:5-trihydroxynaphthalene.

I wish to thank Dr F. Wokes, the Director of the Laboratories, for affording the opportunity to publish this work (which, together with that described in the two succeeding papers, will form part of the thesis for a Ph.D. degree of the University of London), Miss Nora Baxter for technical help in the preparation of the many extracts used and Drs Weiler and Strauss of Oxford for the determinations of carbon and hydrogen.

\section{REFERENCES}

Bernthsen, A. \& Semper, A. (1885). Ber. dtsch. chem. Ges. 18, 203.

Bernthsen, A. \& Semper, A. (1887). Ber. dtsch. chem. Ges. 20, 934.

Coombes, R. (1907). Bull. Soc. chim. Fr. [4], 1, 800.

Daglish, C. (1950). J. Amer. chem. Soc. (in the Press).

Daglish, C. \& Wokes, F. (1948). Nature, Lond., $162,179$.

Mylius, F. (1885). Ber. dtsch. chem. Ges. 18, 463, 2567.

Thomson, R. H. (1949). J. chem. Soc. p. 1277.
Thomson, R. H. (1950). J. chem. Soc. p. 1737.

Tunman, O.\& Rosenthaler, L. (1931). Pflanzen Mikrochemie, 2nd ed., p. 329. Berlin: Borntraeger.

Vogel, A. \& Reischauer, C. (1856). Büchner Neues Rep. für Pharm. 5, 106.

Willstatter, R. \& Wheeler, A. S. (1914). Ber. dtsch. chem. Ges. 47, 2796.

Wokes, F., Organ, J., Duncan, J. \& Jacoby, F. (1943). Nature, Lond., 152, 14. 